values. The implications for the taxonomy of primary biliary cirrhosis are far reaching, as it is hereby differentiated from a similar condition in which sicca complex occurs-namely, chronic active hepatitis. In that condition the prevalence of $\mathrm{B} 8$ is greatly increased, and the genesis of both the liver disease and the sicca syndrome itself may well be on an alternative basis.

We are grateful to Dr J A Sachs for providing control data.

1 Golding PC, Smith $M$, Williams R, Multisystem involvement in chronic liver disease. $A m$ f Med 1973;55:772-82.

2 Thomas HC, Potter BJ, Sherlock S. Is primary biliary cirrhosis an immune complex disease? Lancet 1977; ii :1261-3.

${ }^{3}$ Sherlock S, Scheuer PJ. The presentation and diagnosis of 100 patients with primary biliary cirrhosis. $N$ Engl $\mathcal{F}$ Med $1973 ; 289: 674-8$.

4 Alarçon-Segovia D, Diaz-Jouenen E, Fishbein E. Features of Sjøgren's syndrome in primary biliary cirrhosis. Ann Intern Med 1974;79:31-6.

${ }^{5}$ Moutsopoulos HM, Mann DL, Johnson AH, Chused TM. Genetic differences between primary and secondary sicca syndrome. $N$ Engl $\mathcal{F}$ Med $1979 ; 301: 761-3$.

(Accepted 6 May 1980)

University Department of Medicine, Freeman Hospital, Newcastle upon Tyne NE7 7DN

A N HAMLYN, BSC, MRCP, first assistant in medicine

University Department of Medicine, Royal Free Hospital, London NW3 2QG

DIANA ADAMS, AIMLS, senior technician

SHEILA SHERLOCK, MD, FRCP, professor of medicine

\section{Unprocessed bran and its effect on urinary calcium excretion in idiopathic hypercalciuria}

Idiopathic hypercalciuria occurs in $50-60 \%$ of patients with urolithiasis. ${ }^{1}$ It results from either increased intestinal absorption of calcium (absorptive hypercalciuria) or an abnormality of the renal tubular handling of calcium (renal hypercalciuria). Increasing the fluid intake and restricting dietary calcium are important means of reducing calcium excretion, but long-term reduction by dietary methods is achieved in only about $20 \%$ of patients. ${ }^{2}$ Sodium cellulose phosphate and thiazide diuretics have been used successfully in idiopathic hypercalciuria but may cause side effects ${ }^{134}$ and require patient compliance and medical supervision.

Phytic acid combines with calcium to form the insoluble salt calcium phytate and reduces urinary calcium excretion. ${ }^{5}$ Since unprocessed bran contains phytic acid $(1.7 \mathrm{~g} / 100 \mathrm{~g}$ bran) we decided to study urinary calcium excretion in patients with idiopathic hypercalciuria treated with unprocessed bran.

\section{Patients, methods, and results}

Thirty patients ( 28 male, 2 female) with idiopathic hypercalciuria (urinary calcium concentration exceeding $7.5 \mathrm{mmol}(300 \mathrm{mg}) / 24 \mathrm{~h}$ on two occasions) were entered into the study. Most were aged 40-50 years (range 15-70). Serum and 24-hour urinary calcium, phosphate, magnesium, urea, and creatinine concentrations were measured before, during, and after treatment. A daily sachet of $24 \mathrm{~g}$ unprocessed bran was prescribed in divided amounts with meals. Patients continued with a normal diet throughout.

All serum measurements were normal before and during treatment. The mean pre-trial urinary calcium concentration $( \pm 1 \mathrm{SD}$ ) was $10.6 \pm 1.9$ mmol $(424 \pm 76 \mathrm{mg}) / 24 \mathrm{~h}$. Of the 30 patients, 22 achieved a reduction in urinary calcium with unprocessed bran. The improvement during treatment was highly significant ( $p>0.001$; paired $t$ test). The eight patients who failed to respond included the two women. In the 22 patients urinary calcium excretion rose after treatment had been withdrawn for one month.

\section{Comment}

If urinary calcium excretion can be reduced to normal for a long period in idiopathic hypercalciuria the incidence of recurrent stone formation can be reduced. ${ }^{3}$ An effective dietary regimen is ideal for patients with hypercalciuria as it avoids the possible side effects of drug treatment. Dietary restriction of calcium is difficult to maintain, however, as long-term low calcium diets are intolerable to most patients.

In our study 22 patients (73.3\%) (figure) reduced their urinary calcium excretion by $20-25 \%$, which could well reduce the risk of stone recurrence by $30-50 \%$ over a long period. Possibly larger doses of unprocessed bran would further reduce urinary calcium excretion. The dose used here, however, was close to the upper limit acceptable.

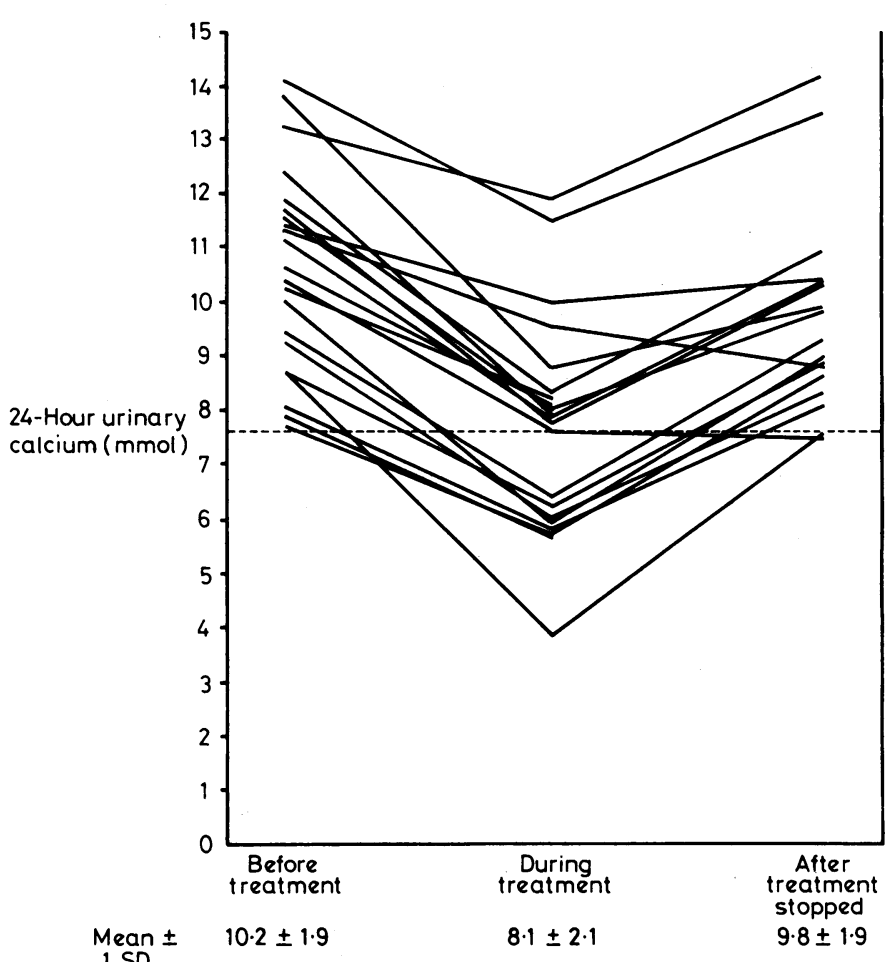

Changes in 24-hour urinary calcium concentrations in 22 patients who responded to treatment. (Urinary calcium: $1 \mathrm{mmol} / 24 \mathrm{~h} \approx 40 \mathrm{mg} / 24 \mathrm{~h}$.)

The eight patients who did not respond to bran treatment might have had "renal" hypercalciuria; we did not, however, attempt to distinguish between the two conditions.

We postulate that three factors may be responsible for the reduction in urinary calcium excretion: $(a)$ the binding effect of phytic acid on dietary calcium may reduce its absorption; $(b)$ a decrease in intestinal transit time produced by dietary fibre may reduce the time available for calcium absorption; $(c)$ bran may have a direct binding effect on dietary calcium.

Unprocessed bran is effective in reducing urinary calcium excretion in most patients with idiopathic hypercalciuria. Bran is inexpensive, free from serious side effects, and should be taken as part of a dietary regimen aimed at reducing intestinal calcium absorption.

${ }^{1}$ Rose GA, Harrison AR. The incidence, investigation and treatment of idiopathic hypercalciuria. Br $\mathcal{F}$ Urol $1974 ; 46: 261-74$.

2 Baker LRI, Mallinson WJW. Dietary treatment of idiopathic hypercalciuria. $B r f$ Urol 1979;51:181-3.

3 Blacklock NJ, Macleod MA. The effect of cellulose phosphate on intestinal and urinary excretion of calcium. Br $\mathcal{F}$ Urol $1974 ; 46: 385-92$.

4 Pak CYC, Delea CS, Bariter FC. Successful treatment of recurrent nephrolithiasis (calcium stones) with cellulose phosphate. $N \mathrm{Englf}$ Med $1974 ; 290: 175-80$.

${ }^{5}$ Hennemann PH, Benedict PH, Forbes AP, Dudley HR. Idiopathic hypercalciuria. $N$ Engl $\mathcal{f}$ Med $1958 ; 259$ :802-7.

(Accepted 2 May 1980)

Norfolk and Norwich Hospital, Norwich, Norfolk NR1 3SR P J R SHAH, FRCS, research senior registrar N A GREEN, MS, FRCs, consultant urologist

Hammersmith Hospital, London W12 OHS

G WILLIAMS, FRCS, consultant urologist 